\title{
EXPERIMENTAL EVALUATION OF AN ADVANCED SPACE SHUTTLE MAIN ENGINE HOT-GAS MANIFOLD DESIGN CONCEPT
}

D. G. Pelaccio, F. F. Lepore, G. M. O'Connor, G. V. R. Rao, G. H. Ratekin, and S. T. Vogt Rockwe11 International/Rocketdyne Division Canoga Park, California

\begin{abstract}
The requirements of higher performance for the Space Shuttle Main Engine (SSME) and future space transportation earth-to-orbit propulsion systems dictate the use of efficient liquid rocket engines with engine cycles that invariably require lightweight, high-pressure, hot-gas ducts and manifolds that exhibit uniform flow, low turbulence levels, and minimal pressure drop characteristics. This study, using an extensively modified, full-scale SSME hot-gas manifold (HGM), established a detailed aerodynamic data base to support development of an advanced, threedimensional, fluid-dynamic analysis computer model. In addition, the advanced SSME hot-gas manifold design used in this study demonstrated improved flow environment (uniformity) in the fuel side turbine exit and transfer duct exit regions.

Major modifications were incorporated in the full-scale HGM flow test article model using two large transfer ducts on the fuel turbine side of the HGM in place of the three small transfer ducts in the present design. Other model features included an increase in the flow areas downstream of the 180-degree turn and in the fishbowl regions. Tests were conducted at a Rockwell International blowdown facility using ambient temperature, high-pressure air that simulated a range of Reynolds numbers from 20 to 60 percent of the SSME rated power level. Detailed steady-state pressure measurement surveys of the flow field on the fuel side of the hot-gas manifold were conducted. Some highfrequency pressure measurements were included to quantify the turbulent nature of the flow in a qualitative
\end{abstract}


fashion. Data were scaled to engine conditions and were compared to similar data for the current SSME three-duct hot-gas manifold design.

The hot-gas manifold flow field data were found to be essentially indpendent of Reynolds number over the range examined. Major flow improvements were observed in the turbine exit/turnaround duct region, where the turbine exit circumferential pressure gradients were reduced by approximately 66 percent. Total and static pressure distributions in the regions downstream of the 180-degree turn were decreased by 75 percent from that exhibited by the present three-duct designs. Separation phenomena in the transfer duct exit planes were also substantially reduced. The maximum engine scaled Mach number exhibited for the two-duct HGM configuration in the transfer duct exit regions was lower by 38 percent from that observed on the current design.

\section{Introduction}

The requirements for higher performance in current and future space transportation earth-to-orbit propulsion systems dictate the use of efficient liquid rocket engines with engine cycles that invariably require lightweight, high pressure, temperature and mass flow, hot-gas duct, and manifolds. In addition, it is also necessary that such propulsion systems be designed with an emphasis on long life, high reliability, and minimum maintenance requirements. Experience obtained during the development and certification of the Space Shuttle Main Engine (SSME), the first large rocket engine designed specifically for reuse, has underscored the importance of optimal design of manifold ducting systems subject to high-pressure, hot-gas streams.

The current SSME hot-gas manifold (HGM) is a double-walled, hydrogen-gas-cooled structural support and fluid manifold, which is shown in Fig. 1. It is the structural backbone of the engine and interconnects and supports the preburners, high-pressure 


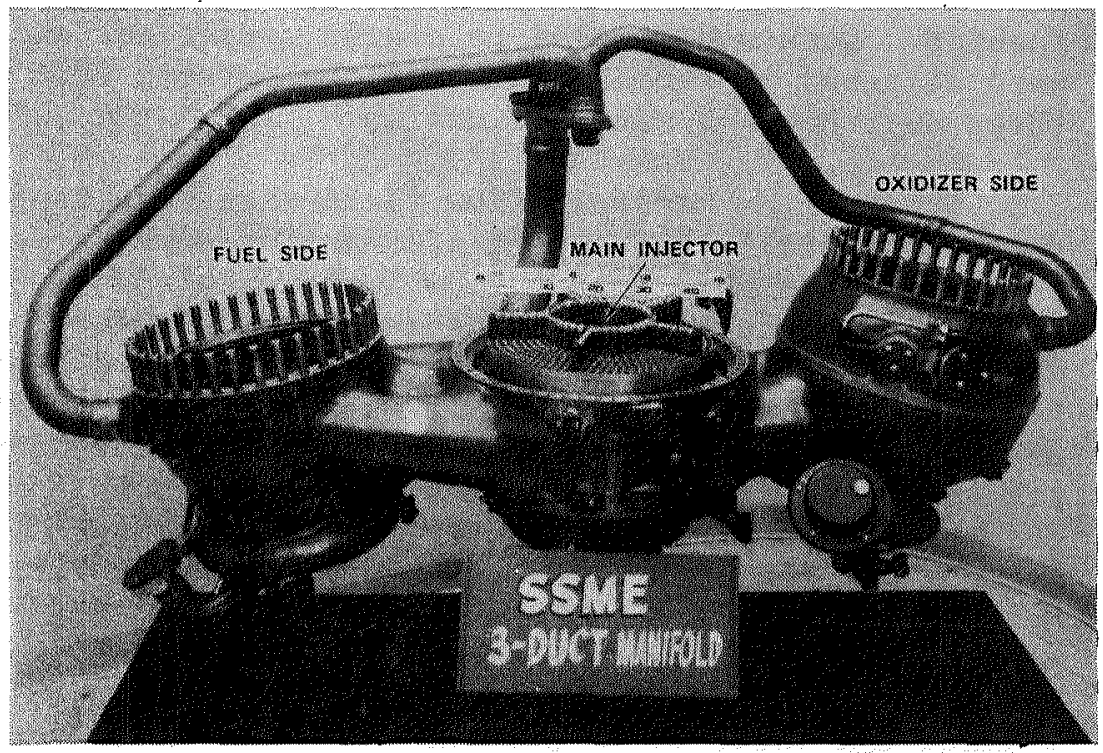

Fig. 1. Current SSME Hot-Gas Manifold

turbopumps, main combustion chamber, main injector, and heat exchanger as shown in Fig. 2. The high-pressure, high-flowrate, high-temperature, hydrogen-rich gas exits the fuel and oxidizer turbopumps and enters the hot-gas manifold. The annular shaped flow channel turns the flow 180 degrees, which then diffuses into large bowl (fishbowl) shaped volumes. The gas is then routed through five hot-gas transfer ducts, three on fuel side and two on the oxidizer pump side, into the main injector torus (racetrack) manifold where it is radially directed into the hot-gas cavity of the main injector. During steady-state operation of the engine, approximately 70 percent of the hot-gas flow is routed through the fuel side while the remalning 30 percent is passed through the oxidizer pump side (Table 1). This condition produces higher dynamic pressures and hence greater aerodynamic loading on the hot-gas manifold fuel side because the mass flow per flow path cross-sectional area is greater than that which is characteristic of the HGM oxidizer pump side.

During the development of the SSME, the flow distribution at the exit of the HGM fuel side ducts was 




Fig. 2. SSME Powerhead

Table 1. SSME HGM Operating Conditions (Ful1 Power Leve1, 109\%)

\begin{tabular}{|l|c|c|c|}
\hline \multicolumn{1}{|c|}{ HGM Region } & $\begin{array}{c}\text { Mass Flow, } \\
\text { Ibm/sec }\end{array}$ & $\begin{array}{c}\text { Pressure, } \\
\text { psia }\end{array}$ & $\begin{array}{c}\text { Temperature, } \\
\text { R }\end{array}$ \\
\hline Fue1 Pump Side & 173.1 & 3589.5 & 1680.6 \\
Oxidizer Pump Side & 68.1 & 3589.1 & 1454.5 \\
\hline
\end{tabular}

Identified as being nonuniform and exhibiting largescale separated flow regions. Typically, a large separation region is situated in the lower portion of the center transfer duct while smaller separation regions exist at the inner duct wall position of the outer transfer ducts. These flow nonuniformities at: the exit of the fuel side transfer ducts in the current SSME hot-gas manifold design produce local high velocity flow regions that impinge on the main injector liquid oxygen (LOX) posts producing a high 
aerodynamic force on the posts. Nonuniformities in the back pressure sensed by the high-pressure fuel turbine have resulted in oscillatory loads on the turbine blades. Highly turbulent flow levels have also been observed throughout the HGM flow circuit. These flow characteristics degrade lifetimes associated with the main injector LOX posts, high-pressure fuel turbopump (HPFT) blades, and duct cooling liners that have on occasion experienced cracking.

Additionally, flow fields associated with such manifold systems are complicated by the fact that they typically exhibit highly three-dimensional, separated, turbulent, swirling-flow features that make analysis difficult. At present, computational fluid dynamic analysis tools (Ref. 1-3) are being established to support in the design of future SSME type manifold systems. Thus, verification of these new computational models to a detailed data base, which represents a typical HGM flow type system, is essential to ensure confidence in their predictive accuracy.

In this study, a full-scale, modified, fuel-side SSME was evaluated using a high-pressure ambienttemperature, air blowdown system, which was directed toward improving the overall flow distribution and decreasing turbulence levels in the turbine exit, turnaround duct, and transfer duct regions compared to the present SSME HGM design. Detailed steady-state pressure measurement surveys, using wall static ports, total pressure Kiel probes, directional probes, and total pressure rakes, of the HGM fuel-side flow field were performed. Some high frequency pressure measurements were also included to quantify the turbulent nature of the flow.

Data were scaled to engine conditions and were compared to similar data for the current SSME threeduct HGM design. From these comparisons, flow system improvement trends associated with the advanced SSME hot-gas manffold design were then established. 


\section{Hot-Gas Manifold Concept Definition}

A number of advanced HGM fuel-side design concepts were conceived and evaluated (Ref. 4). The concept options generated were guided by two major goals: (1) to produce a more favorable flow environment for the SSME main combustion chamber LOX injector posts and HPFT turbine by improving transfer duct flow flow distribution, velocity profile uniformity, decreasing turbulence levels, and minimizing streamline pressure losses; and (2) compatibility with flow conditions associated with projected increased SSME power levels. These HGM concepts were evaluated in terms of their flow aerodynamic thermodynamic, structural, system integration, and fabrication characteristics. From this design option task, an enlarged area, fuel-side, two-transfer duct concept was selected as the HGM configuration that was fabricated, tested, and analyzed in this study.

The selected design has the following key features incorporated on the fuel turbine side of the manifold: (1) two 6.50-inch diameter ducts that increase flow area approximately 30 percent over the current configuration decreasing the flow dynamic head proportionally, (2) increase in turnaround duct area, 8-degree outer wall flairing after the 180-degree turn to decrease the flow dynamic head, (3) slightly rounded duct inlets to assist in turning the flow into the transfer ducts, (4) slightly rounded duct outlets to assist in distributing the flow around the main injector LOX post bundle, (5) flaired transfer ducts into the fuel preburner housing to assist in directing flow into transfer ducts and decreasing the HPFT exit pressure gradient, (6) faired transfer ducts into the main injector housing to assist in distributing flow around the main injector LOX post bundle, (7) increasing the HGM fishbowl volume by eliminating the present liner element to decrease the flow dynamic head in this region, and ( 8 ) compatibility to incorporate contoured turning vanes to assist in distributing flow into the transfer ducts and decreasing the HPFT exit pressure gradient. A schematic layout of this advanced HGM design identifying its key features is shown in Fig. 3. 


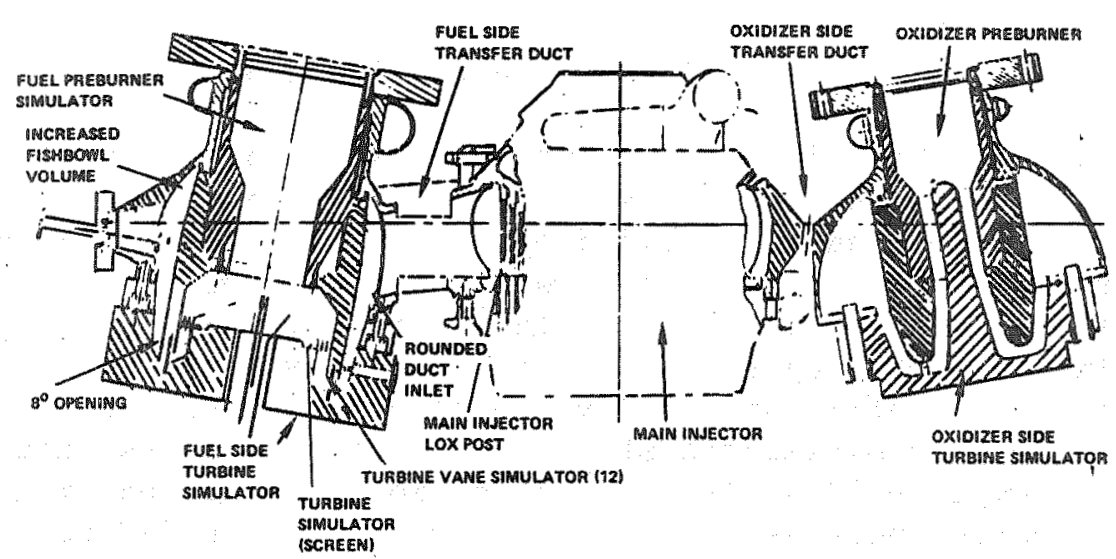

A. SIDE VIEW

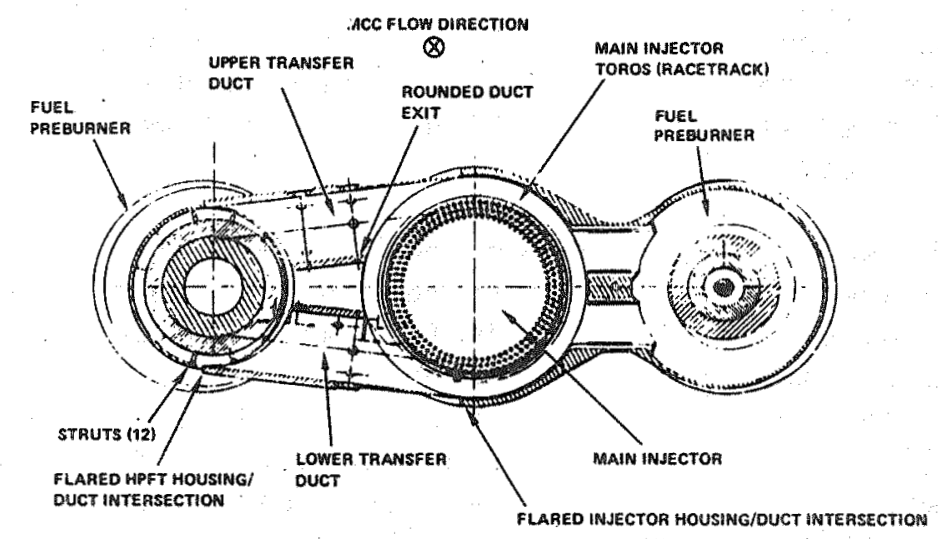

B. TOP VIEW

Fig. 3. Two-Duct HGM Air Flow Test Powerhead Configuration

A comparison of the two-duct HGM to the current SSME HGM design is displayed in Table 2. The major area increase in the turnaround duct exit area, fishbowl cross-sectional area, and duct cross-sectional area associated with the two-duct HGM design tends to decrease the flow dynamic pressure for a given operational setting, which assists in gradual turning of the flow. These HGM design features also improve duct flow distribution, uniformity, and decrease flow turbulence, as well as assist in producing uniform flow conditions at the HPFT exit. 
Table 2. HGM Design Comparisons

\begin{tabular}{|c|c|c|c|}
\hline Feature & $\begin{array}{l}\text { SSME } \\
\text { HGM } \\
\text { Current } \\
\text { Design }\end{array}$ & $\begin{array}{l}\text { Flow Study } \\
\text { Design Model } \\
2 \text { Ducts }\end{array}$ & $\begin{array}{l}\text { Percentage } \\
\text { Difference } \\
\text { 2-Duct Design } \\
\text { SSME Design }\end{array}$ \\
\hline Turnaround Duct & FPL** & RPL (FMOF)*** & -- \\
\hline $\begin{array}{l}\text { Turnaround Duct } \\
\text { Exit Area }\end{array}$ & 29.5 in. $^{2}$ & $49.68 \mathrm{in.}^{2}$ & 68.5 \\
\hline $\begin{array}{l}\text { Fishbow1 Cross- } \\
\text { Sectional Area }\end{array}$ & $6.05 \mathrm{in.}^{2}$ & 10.6 in. $^{2}$ & 75.3 \\
\hline $\begin{array}{l}\text { Duct Cross- } \\
\text { Sectional Area }\end{array}$ & 51 in. $^{2}$ & 66.3 in. $^{2}$ & 30.0 \\
\hline $\begin{array}{l}\text { Faired Duct } \\
\text { Inlets* }\end{array}$ & Yes & Yes & -- \\
\hline $\begin{array}{l}\text { Faired Duct } \\
\text { Outlets }\end{array}$ & No & Yes & -- \\
\hline \multicolumn{4}{|c|}{$\begin{array}{l}\text { *Slightly Rounded } \\
\text { **ull Power Level Configuration } \\
\text { **Rated Power Level, First Manned } \\
\text { Orbital Flight Configuration }\end{array}$} \\
\hline
\end{tabular}

Hot-Gas Manifold Test Article Design/ Fabrication/Instrumentation

A low-cost philosophy guided the design and fabrication of the hot-gas manifold test article. An existing surplus SSME hot-gas mantfold was modified to produce the advanced, two-duct HGM test article. Ad-ditionally, where applicable, internal flow simulation components and instrumentation techniques that were successfully demonstrated in past HGM flow studies for the present SSME engine design (Ref. 5) were used. Numerous steady-state and high-frequency pressure instrumentation ports were incorporated in the fuel side of the model to define the flow field in detail from the model inlet to the transfer ducts exit. The test model was designed for a working pressure of 300 psia.

The oxidizer flow was modeled with a preburner/ turbine simulator and turnaround duct. Flow enters the oxidizer preburner, which then transitions into an annulus passage that has six long, equally spaced blades to impart a swirl velocity component to the flow. The swirling flow is typical of turbine exit 
flow conditions. The flow then enters the oxidizer turbine exit simulator where the flow direction is changed 180 degrees and exits into the large oxidizer side HGM fishbowl region (Fig. 3). In the SSME (Fig. 2 ), the oxidizer side HGM fishbowl region contains the heat exchanger component. Flow then exits through the two oxidizer transfer ducts into the main injector. Aluminum and Cres were the materials used in oxidizer side simulator hardware designs. This design simulates the gross features of the SSME oxidizer flow field but lacks proper simulation of flow field details. The degree of simulation designed into the test model was considered adequate because the oxidizer flow field does not influence the fuel side transfer duct flow field to a great extent. This is considered a good assumption because only approximately 30 percent of the total HGM gas flow goes through the oxidizer side of the HGM, while the remaining 70 percent is passed through the fuel side during hot-fire engine operation, as previously mentioned.

In contrast to the oxidizer side simulator design, the fuel preburner/turbine simulation hardware (Fig. 4 and 5) was designed to simulate an SSME fuel side flow field in detail. Like the oxidizer side simulator, the fuel side simulator was based on a design that was successfully demonstrated in past HGM flow studies. Past flow study test data showed that this simulator design produced an HGM fuel side flow that correlated well with that measured in an SSME engine. In this design, the flow enters the fuel preburner simulator where it is manifolded into an annular passage. At the annular passage entrance, a turbine simulator screen is placed to produce flow effects that are characteristic of those associated with a 15-degree swirl angle clockwise if viewed in the direction of the flow downstream of the screen, which is typical of SSME HPET exit flow conditions at rated power level. Constant velocity conditions are produced by varying the orifice diameter as a function of radial position. The screen was designed for a pressure loss coefficient $(\Delta P / q)$ of 


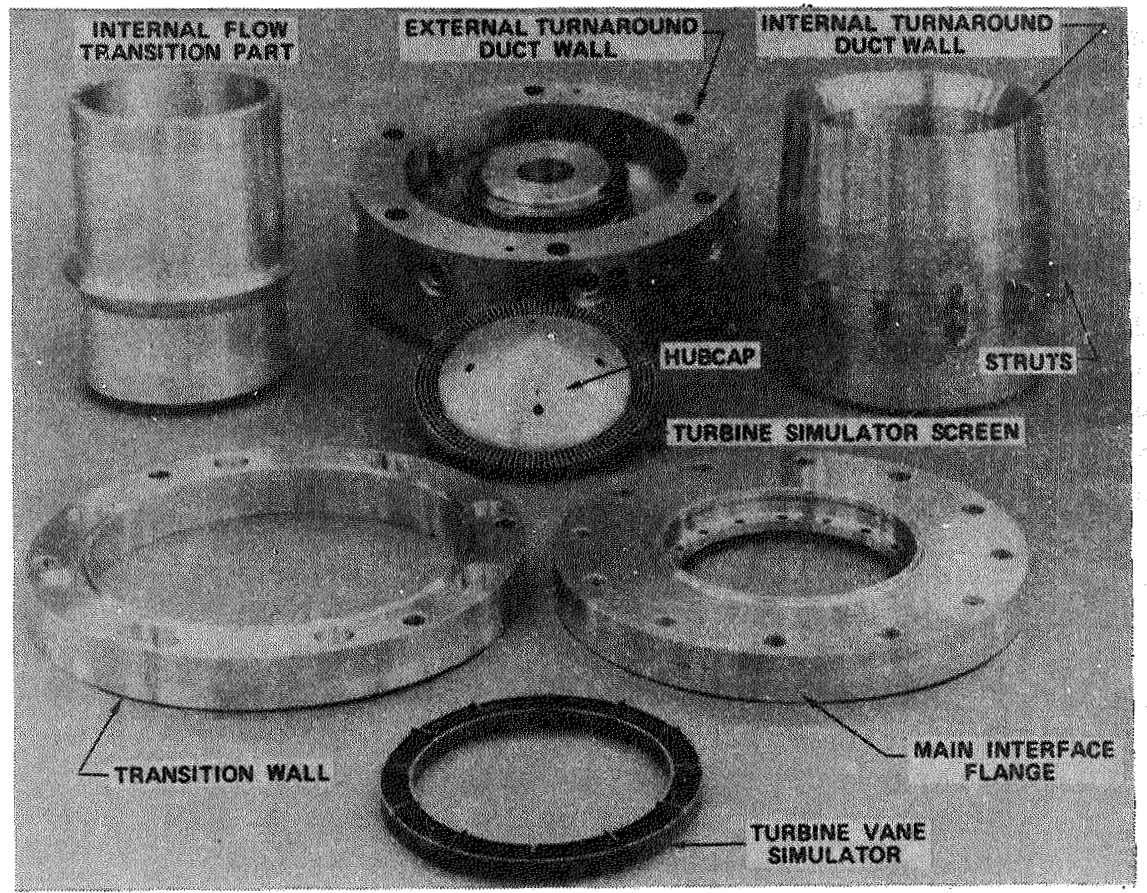

Fig. 4. Fuel-Side Simulator Components

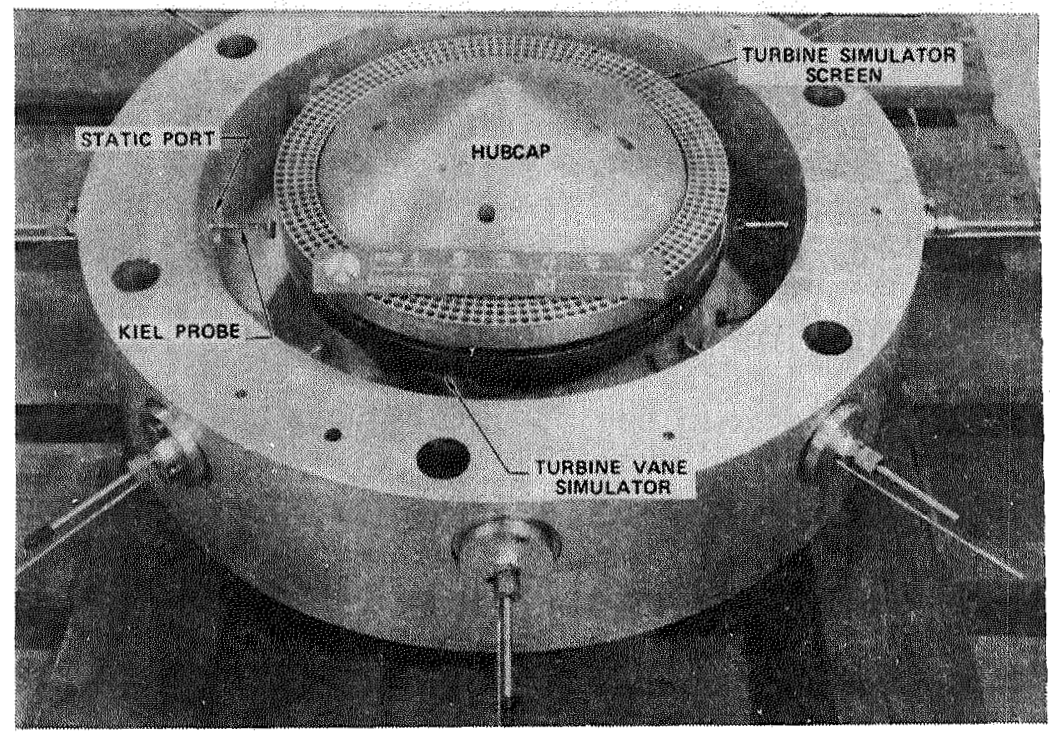

Fig. 5. Fue1-Side Turbine Simulator Assembly 
5.6 psid, which is approximately 25 percent of that exhibited by the HPFT while still having enough resistance to stabilize flow exit conditions. Twelve thin fins, which span the width of the annular channel, are positioned just downstream of the screen exit in an equally spaced circumferential fashion. These fins sinulate flow interference blockage associated with the turbine exit coolant liner supports. They are set on an angle of attack to the flow because of the swirl angular velocity component, and therefore add eddy vortex (vorticity) structure to the flow. The flow then changes direction, 180 degrees, in the turnaround duct region. The turnaround duct geometry simulates that used on the Space Shuttle Columbia's first set of flight engines known as the First Man Orbital Flight (FMOF) configuration. Downstream of the 180-degree turn, the outer wall of the annular flow channel is designed with an outward 8-degree taper. Twelve large support struts are then equally spaced circumferentially in the annular passage at the fishbowl entrance and simulate major structural components associated with the engine in this region. In the design of the HGM fuel-side fishbowl, the coolant liner was removed to increase the fishbowl volume. Two 6.5-inch constant ID ducts (Fig - 6) were integrated into the fishbowl and main injector housing, completing the fuel-side gas flow path to the main injector assembly. The coolant liner on the fuel stde of the main injector was removed to accommodate the large transfer ducts. The two-duct HGM design also incorporates slightly rounded entrance and exit duct geometries and flush internal surfaces at the outer intersection points between the transfer ducts and the HGM fuel preburner and main injector housing (Fig. 3). Like the oxidizer simulator hardware, the fuel-side simulation hardware was designed to be made of aluminum and Cres material.

The SSME powerhead main injector was designed to be removable for ease in instrumentation and configuration changes. A modified SSME main combustion chamber (MCC), which incorporates the addition of a long throat ASME flow metering type nozzle is bolted 


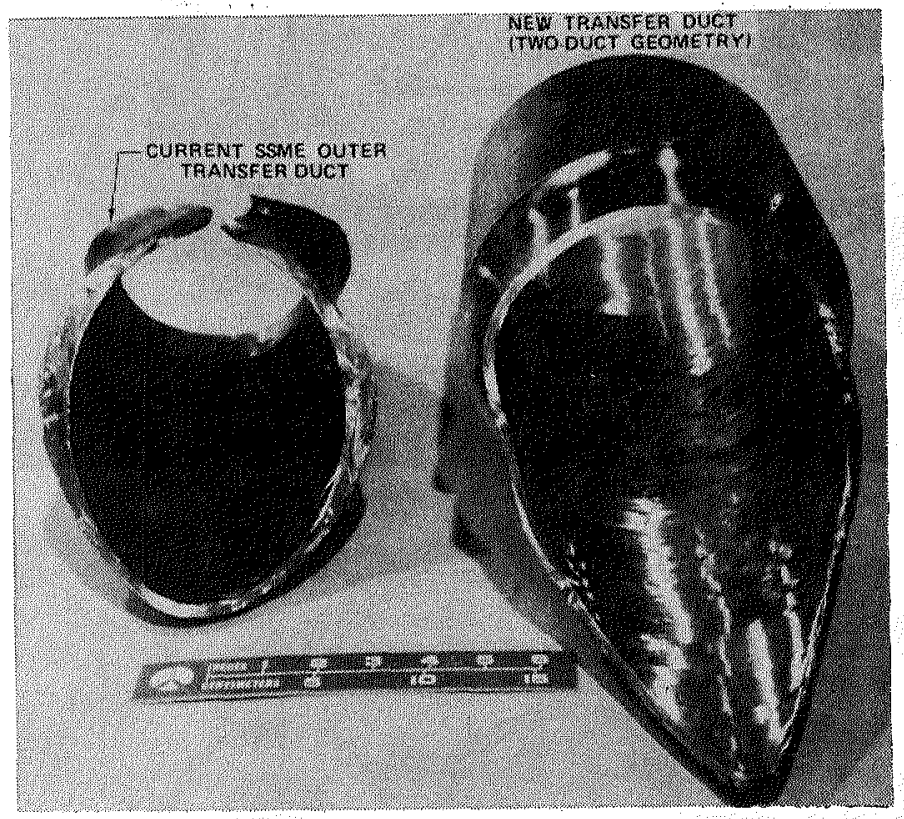

Fig. 6. Comparison of Current SSME Outer and New Transfer Duct

to the HGM main injector exit face. The flow metering nozzle chokes the flow maintaining high pressure within the flow model and also functions as a model total flow metering device.

Integration of an extensive amount of pressure instrumentation was incorporated into the fuel side test model. The model instrumentation measurement locations were placed to give detailed steady-state flow field definition at the model inlet, turnaround region, fishbowl entrance, transfer duct entrance, and exit planes. High frequency instrumentation is included in the model to give a qualitative assessment of the turbulent nature of the flow. A layout of instrumentation (location and type) is shown in Fig. 7 and listed in the legend given in Table 3, respectively. The upper transfer duct was designed to accept a pressure survey at the entrance. The entrance pressure rake layout configuration is shown in Fig. 8. Flow conditions are defined at both transfer duct 


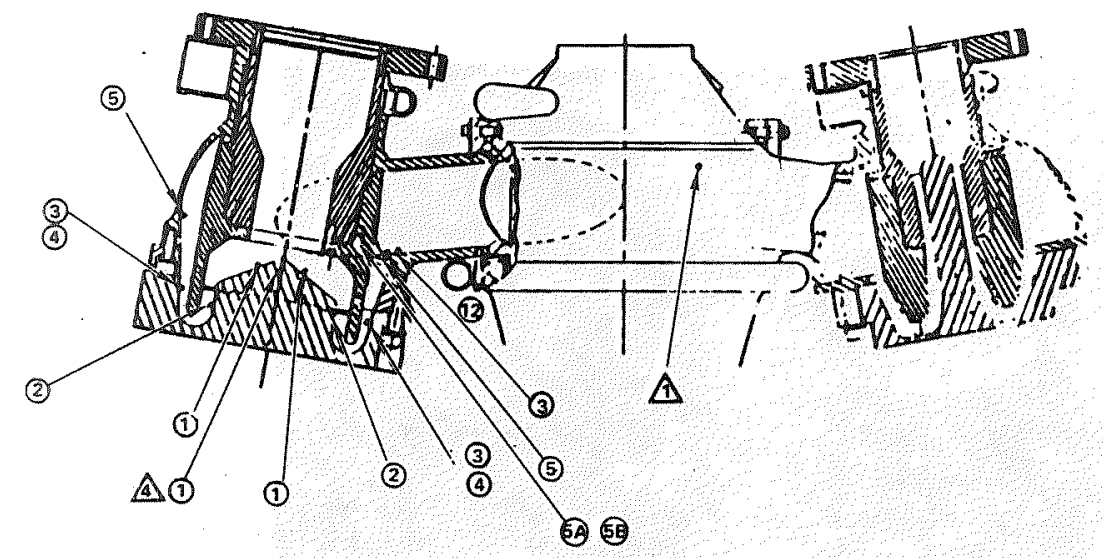

A. SIDE VIEW

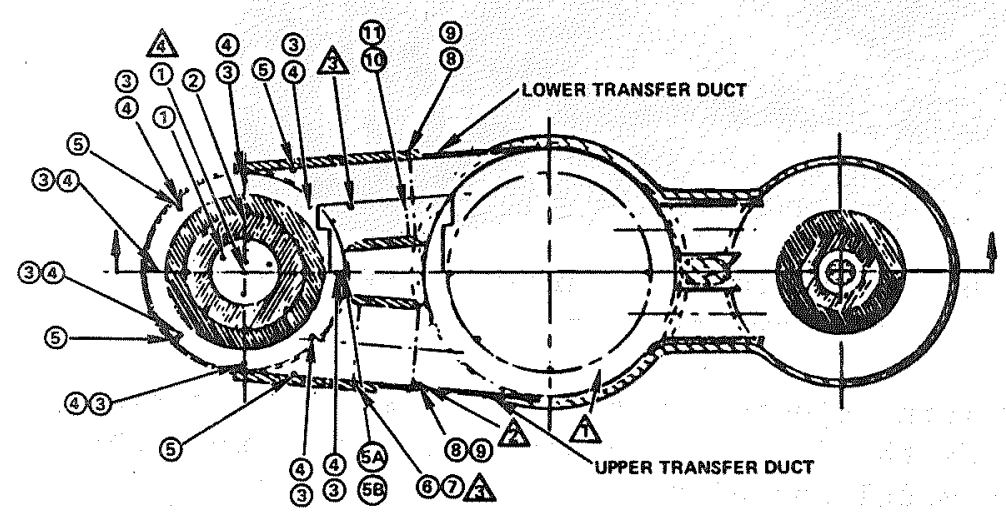

B. TOP VIEW

Fig. 7. Instrumentation Layout

exits (Symbols 8 and 9, Fig. 7) by placement of exit total pressure survey rakes shown in Fig. 9. In the lower duct, a pressure rake element (Fig. 7) was placed to measure the inner wall region flow field at a position 1.25 inches upstream of the exit rake plane. These total pressure rake elements were designed to be easily removable, have rotational capability, and be interchangeable with all rake locations. The three basic rake element types used are displayed in Fig. 10. When assembled the cross-sectional area blockage of the rakes was no greater than 9 percent of the total transfer duct cross-sectional area. 
Table 3. Test Article Instrumentation Legend

\begin{tabular}{|c|c|}
\hline Symbol & Locatior/Type \\
\hline$\frac{A}{A}$ & $\begin{array}{l}\text { Steady-State Pressure Measurements } \\
\text { Model Inlet/3 Static - } 1 \text { Total } \\
\text { Screen Exit - Upstream 180-Deg Turnaround/Static } \\
\text { Downstream } 180 \text {-Deg Turnaround/Static } \\
\text { Downstream 180-Deg Turnaround/Tota1 } \\
\text { Fishbowl - Entrance Upstream of Transfer Duct } \\
\text { (3-D Probes) } \\
\text { FishbowI Entrance/Static } \\
\text { Fishbowl Entrance/Total } \\
\text { Transfer Duct Entrance/Static } \\
\text { Transfer Duct Entrance/Total } \\
\text { Transfer Duct Exit Plane/Total } \\
\text { Transfer Duct Exit Plane/Static } \\
\text { Transfer Duct Exit Inner Wa11/Static } \\
\text { Transfer Duct Exit Inner Wal1/Total } \\
\text { Main Combustion Chamber/Total } \\
\text { CGlP - Racetrack Flow } \\
\text { Upper Transfer Duct - Exit } \\
\text { Upper Transfer Duct - Entrance } \\
\text { Fuel Side Model Inlet }\end{array}$ \\
\hline
\end{tabular}

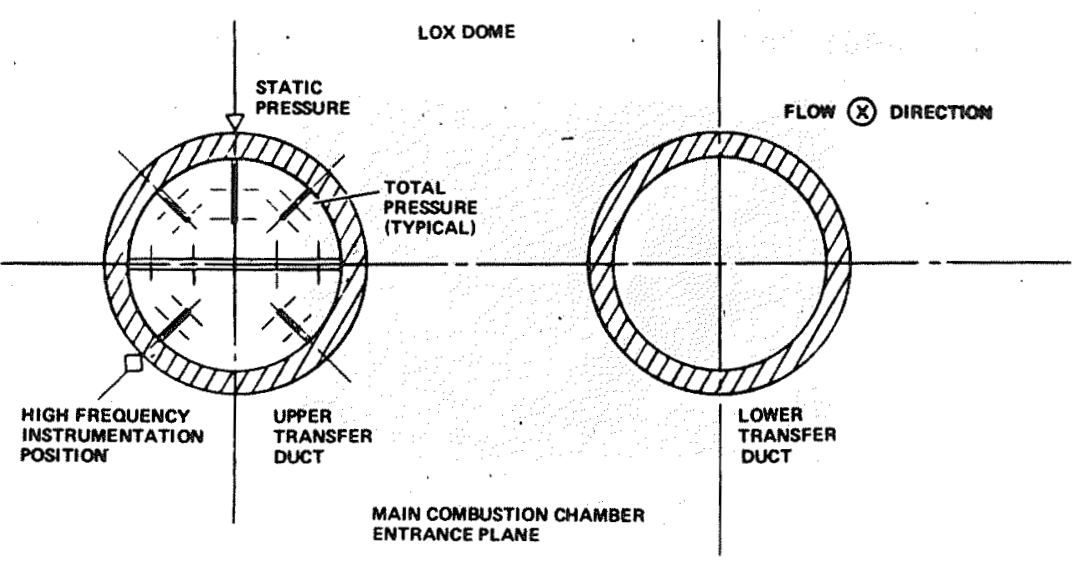

Fig. 8. Upper Transfer Ducts Entrance Rake Configuration 


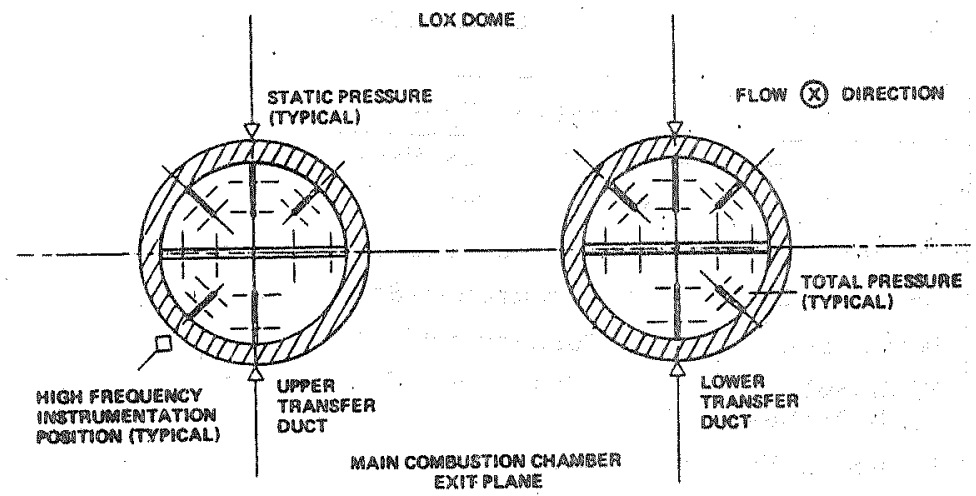

Fig. 9. Transfer Ducts Exit Rake Configuration

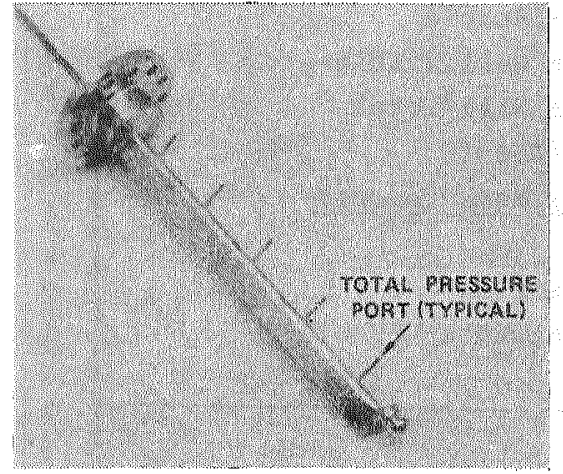

A. LARGE RAKE

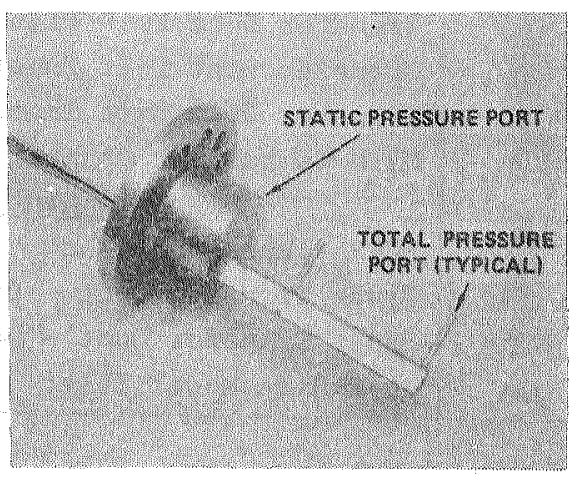

B. MED IUM RAKE

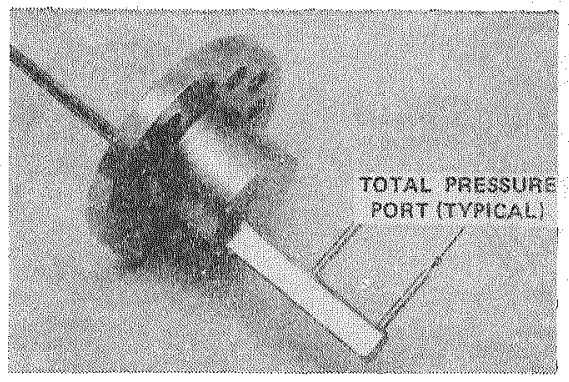

C. SMALL RAKE

FIg. 10. Total Pressure Rakes (Typlcal) 
Total pressure Kiel probes were used downstream of the 180-degree turnaround reglon (Fig. 11) and threedimensional directional probes were used to the map flow at the fishbowl entrance plane (FIg. 12).

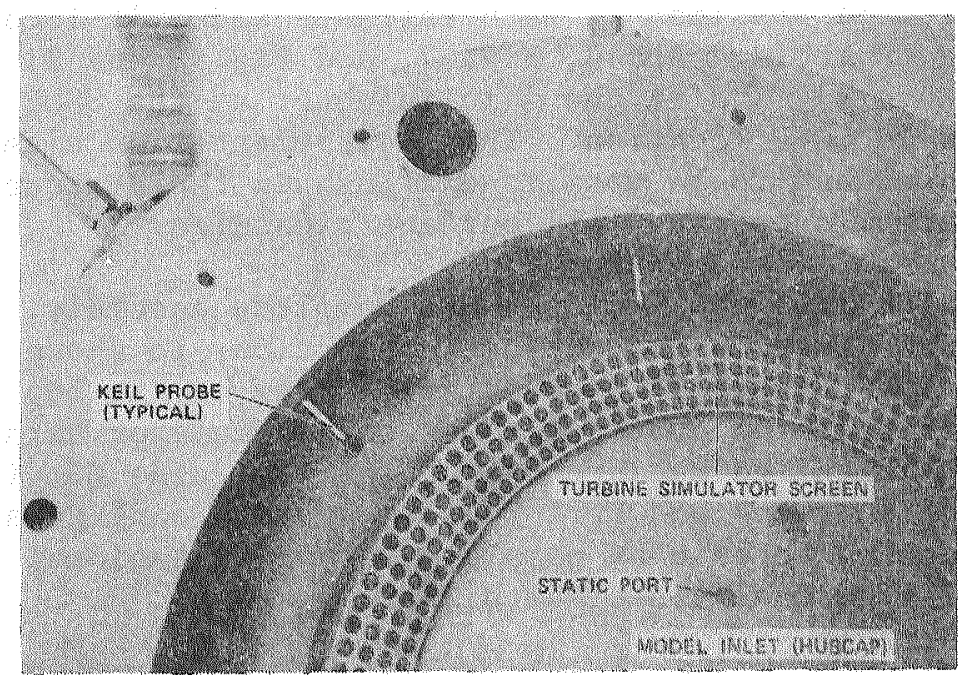

Fig. 11. Fuel side Turbine Simulator (closeup)

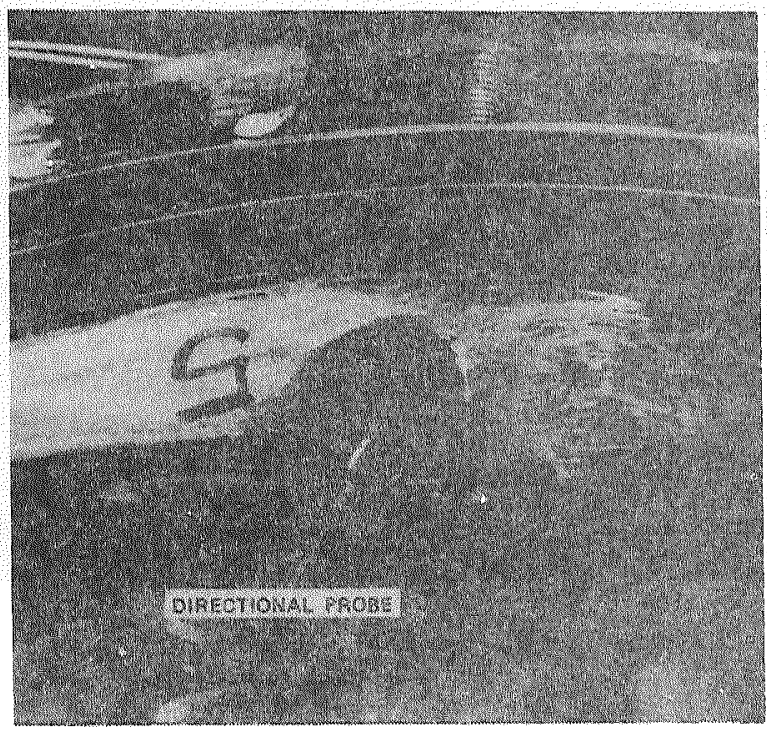

Fig. 12. Directional Probe Installation (Typical) 
High-frequency pressure instrumentation was incorporated in the model at four positions. These locations are at the model inlet position on the preburner centerline upstream of the turbine simulator screen (Symbol 4, Fig. 7), at the upper transfer duct outer wall position at both entrance and exit locations (Symbols 2 and 3, Fig. 7, and Fig. 8 and 9 , respectively), and in the main injector at the SSME manifold CGIP location. This instrumentation element was designed to be positioned flush in the surface to measure fluctuating wall surface pressures.

The advanced two duct HGM complete assembly, including installation of instrumentation, is shown in Fig. 13. Figure 14 is a detailed view of the top enlarged transfer ducts and fuel side simulator hardware. Detailed measurement of the fuel side HGM internal surfaces was performed to support configuration definition for use by complementary computational model flow analysis efforts (Ref. 2 and 3 ).

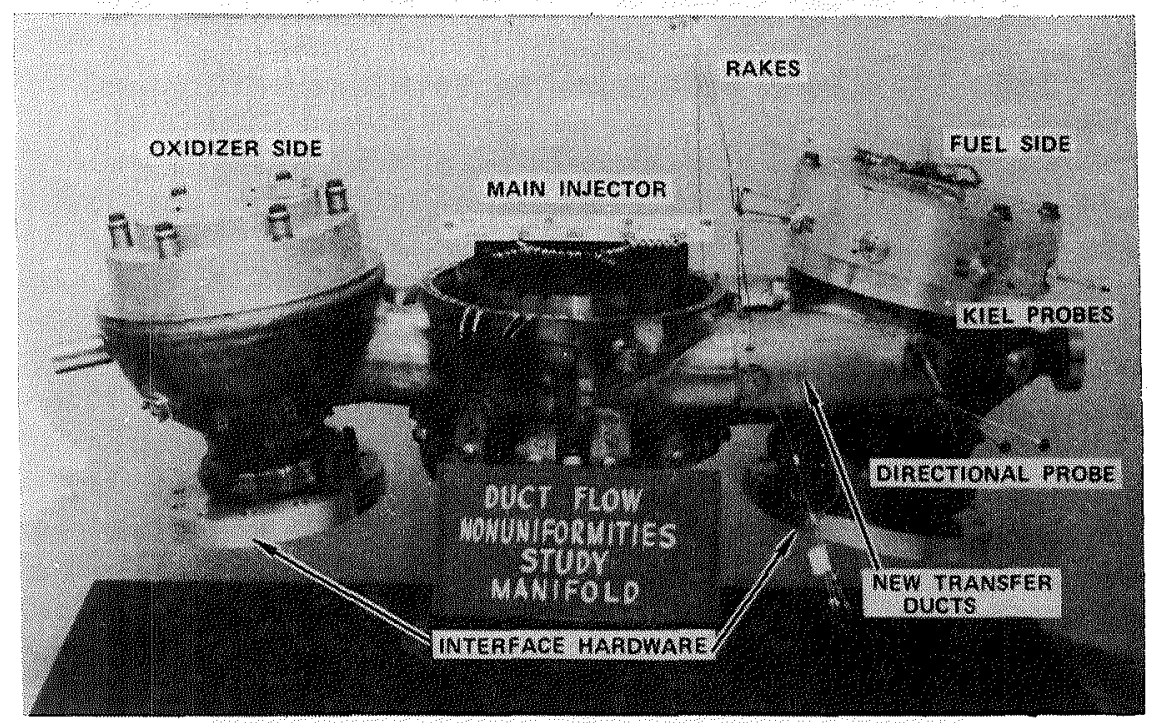

Fig. 13. Advanced Hot-Gas Manifold 


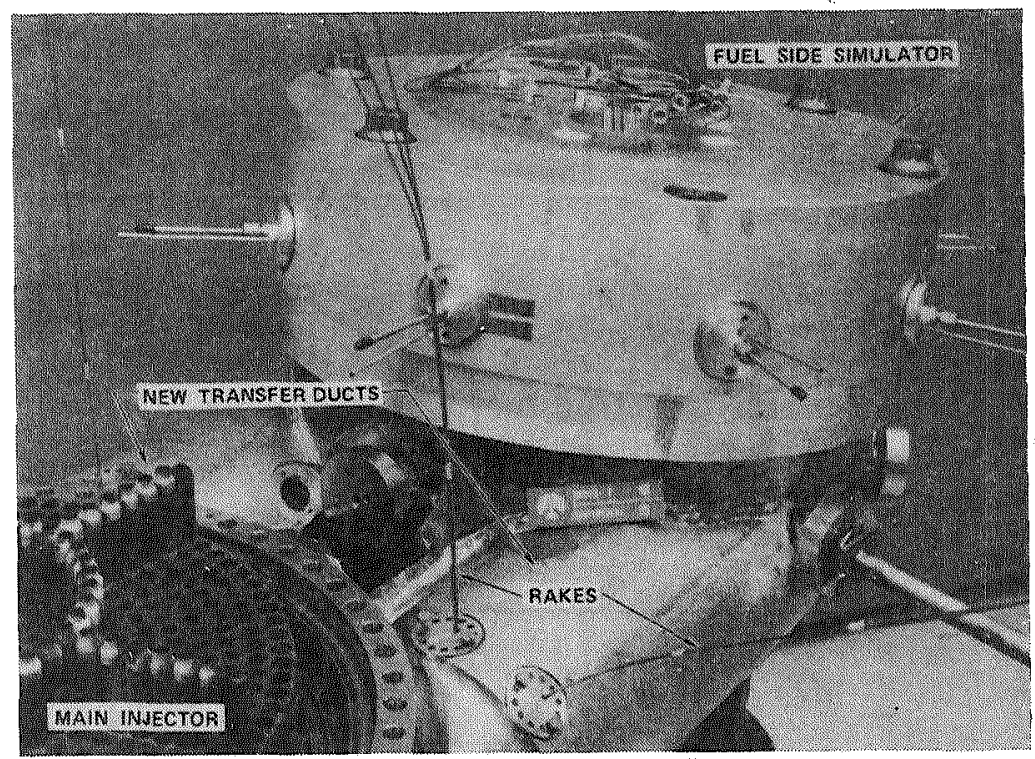

Fig. 14. Advanced HGM - Fuel Side

\section{Test Facility/Operations}

A high-pressure, air-blowdown test facility at Rockwell's Nicrth American Operations Aerospace Laboratory in E1 Seg ndo, California, was used. The blowdown facility was used to simulate up to 69 percent of the SSME rated power level Reynolds number at steady-state conditions for approximately 6 to 10 seconds, while transfer duct average Mach number (M) is essentially matched. A comparison of facility conditions to the SSME for key test simulation parameters is shown in Table 4. With these key simulation parameters in the general range of engine conditions, accurate scalability of the air flow test data to engine system conditions is ensured.

A schematic layout displaying the main elements of the test facility is presented in Fig. 15. These main elements include the high-pressure air supply tank, main 18-inch valve, downstream plenum flow leg tee, 10-inch fuel and 6-inch oxidizer side flow legs with metering orifices, test model installed in the 
Table 4. Engine/Facility Comparison

\begin{tabular}{|l|c|c|}
\hline \multicolumn{1}{|c|}{ Parameter } & Engine* & $\begin{array}{c}\text { Two-Duct HGM } \\
\text { Test Facility, Air }\end{array}$ \\
\hline Pressure, psi & 3000 & 300 \\
Flowrate, lbm/sec & 152 & 84 \\
Mach Number & 0.1 & 0.16 \\
Reynolds Number, $1 / f t$ & $1.90 \times 10^{7}$ & $1.30 \times 10^{7}$ \\
Percent, Reynolds & 100 & 69 \\
Number & \\
\hline *Rated Power Level Conditions & \\
\hline
\end{tabular}

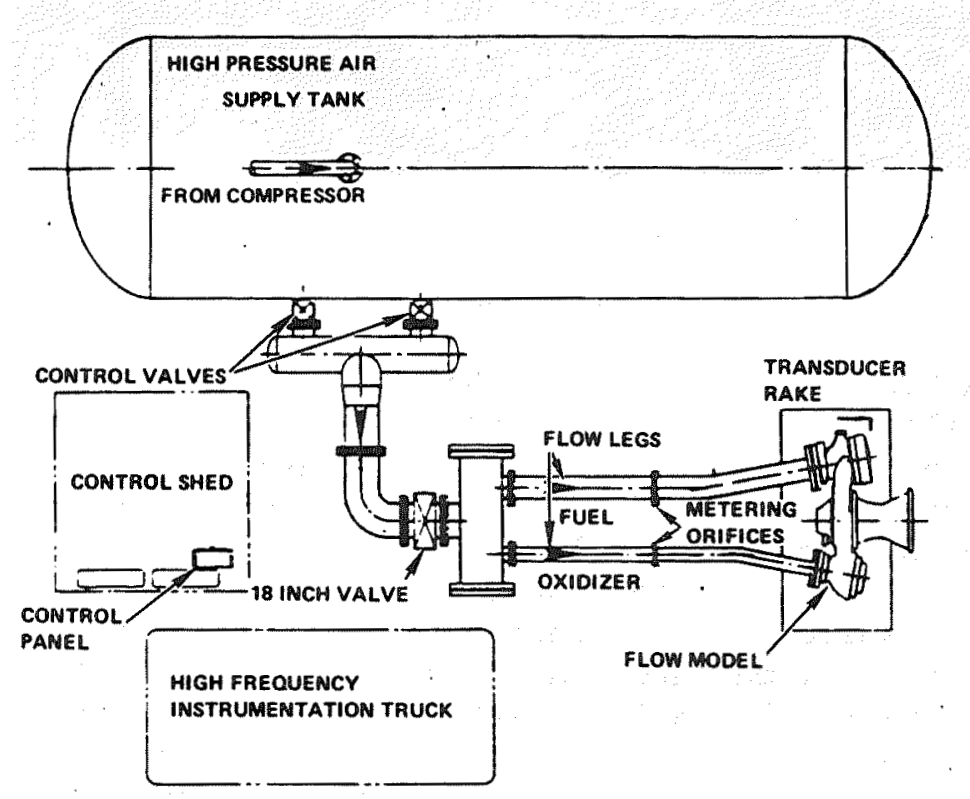

Fig. 15. NAAO Powerhead Blowdown Facility

support stand and the high frequency instrumentation recording room (truck). A detailed view of the flow model installed at the test facility is shown in Fig. 16 .

The high pressure supply air tank is supplied by Cooper Bessemer, 11-stage, centrifuga1, 4500horsepower compressor up to a maximum pressure of 300 psia. The facility is controlled manually by 




Fig. 16. Flow Model Installed

three pneumatically operated ball valves upstream of the test flow model. The upstream fuel and oxidizer feed leg flow metering orifices were sized in such a manner to properly simulate the mass flow split typical of SSME powerhead operation ( 70 percent fuel, 30 percent oxidizer).

Standard gauge and differential pressure transducers were used for steady-state pressure measurements. Up to 95 channels of steady-state instrumentation were recorded at $1 \mathrm{millisecond} \mathrm{sampling} \mathrm{inter-}$ vals on the laboratory's data acquisition system. After testing, these data were then transferred by tape to Rockwell's IBM main frame computer where detailed reduction and analysis of the data were conducted. High-frequency pressure instrumentation was recorded on a tape recorder. These tapes were then analyzed on Rocketdyne's Analog Analysis System.

Due to the large number of steady-state pressure measurements required (number of transducers required) to properly define the three-dimensional flow field, three instrumentation configurations were required to fully characterize the flow field for a 
glven Reynolds number flow condition. Facility metering orlfices, model inlet, and supper and lower transfer duct static pressure measurements were recorded in al1 tests to ensure repeatability between individual tests that were run at identical test conditions. Tests were run at three $R_{D}$ (Reynolds number based on transfer duct diameter) flow conditions $\left(2.1 \times 10^{6}\right.$, $5.0 \times 10^{5}$, and $7.0 \times 10^{6}$ ) to determine the influence of Reynolds number on the fuel-side flow field.

\section{Results}

The advanced, two-duct HGM data were scaled to engine conditions and compared to data associated with the present SSME three-duct HGM design. Discussion of the scaling techniques used in converting full-scale, cold-flow model data to simulated hotfire conditions are presented in the Appendix. Detailed discussions of data concerning major hot-gas manifold flow field features are presented in Ref. 4, while data pertaining to engine operation and improvements associated with the advanced, two-duct HGM design concept are examined below.

It should be noted when examining the data that a 16-degree swir1 was induced in the fuel-side flow at the turbine simulator screen in the clockwise direction (upper to lower transfer duct direction) when viewed from the top (LOX dome) of the flow model. In the fuel-side simulator region, the circumferential location was defined as 0 degree between the two transfer ducts, which then increase in location position angle in the counterclockwise direction when viewed from the top of the model (Fig. 17). The upper transfer duct (UTD) intersects the fuel-side simulator in a circumferential position sector between 15 and 85 degrees while the corresponding lower transfer duct (LTD) position intersects the fuel side between 275 to 345 degrees. The 180-degree position was defined opposite the region between the transfer ducts. 


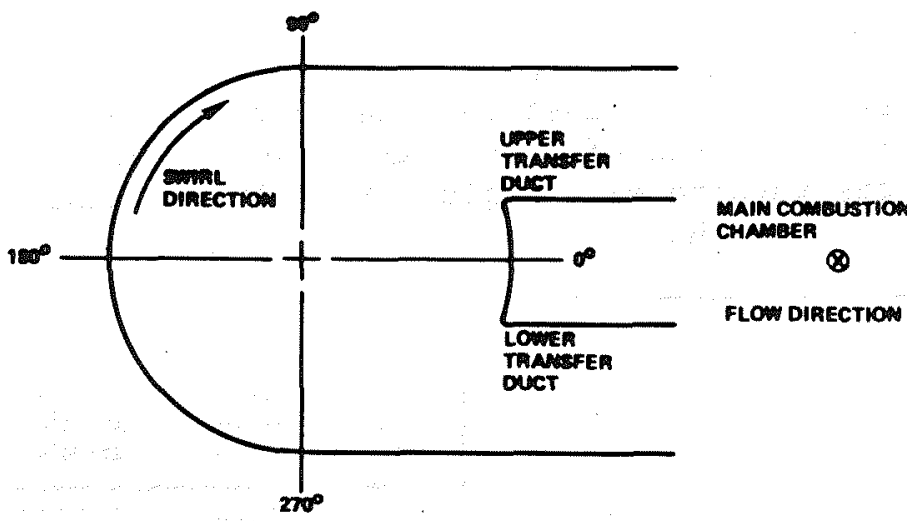

Fig. 17. Two-Duct HGM Fuel-Side Circumferential Location Legend

Test repeatability was considered quite good between individual tests at the approximate same operating conditions. In general, little or no Reynolds number effect was observed throughout the HGM fuelside flow system except at the fishbowl entrance plane where the local dynamic pressure circumferential variations increased by approximately one dynamic pressure head at the low Reynolds number test condition $\left(\operatorname{Re}_{\mathrm{D}} 2.6 \times 10^{6}\right)$. These results give confidence that at the high Reynolds number test conditions (69 percent of SSME rated power leve1 Reynolds number), the critical Reynolds number conditions have been exceeded as is characteristic of engine operation. This implies that major separation and turbulent flow structure features present in a hotgas manifold operated at engine conditions should also be present in the hot-gas manifold cold-flow model when operated at high Reynolds number test conditions.

The SSME HGM at the exit of the high pressure fuel turbopump imposes on the turbine considerable circumferential variations in static and total pressure. This effect is due to the compactness of the manifold and to its one-sided discharge through the transfer tubes. The predictions have been confirmed on SSME hot-firing tests, as well as by past HGM air-flow test studies (Ref. 5). The two-duct HGM 
greatly reduced the pressure (flow) nonuniformities in the turbine exit/turnaround duct region compared to the present three-duct SSME design. A reduction of about two-thirds of the total pressure variation around the turbine exit region (Fig. 18) is achieved by the two-duct HGM design.

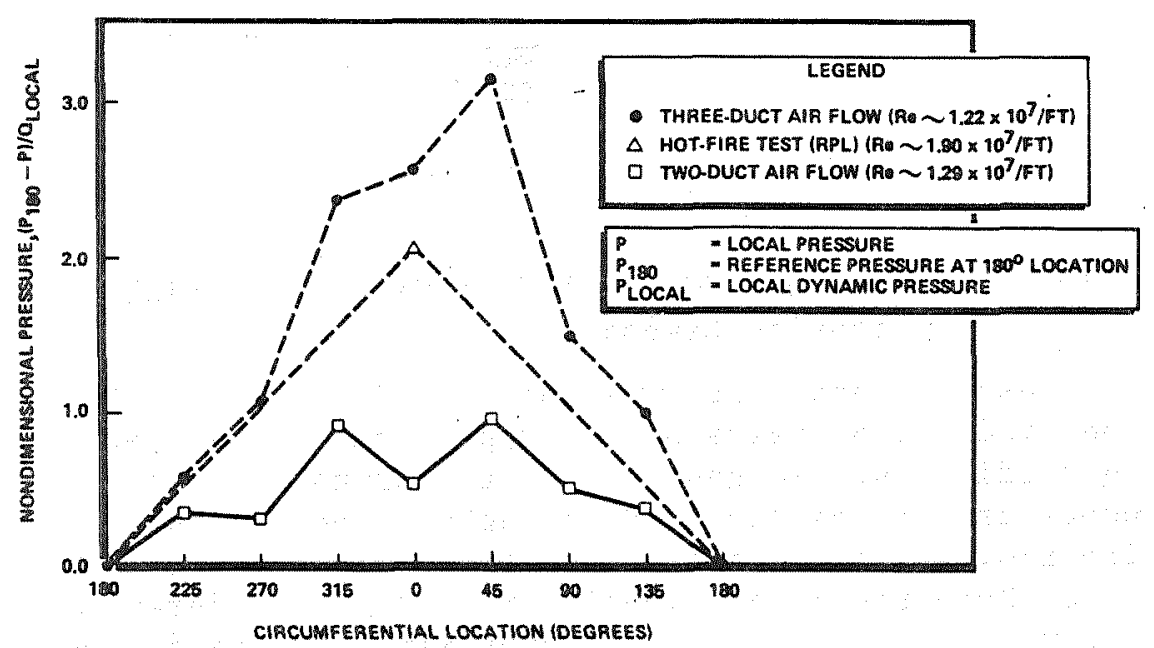

Fig. 18. Circumferential Static Pressure Variation at Turbine Exit

The turbine simulator screen in the flow model enforces constant velocity conditions implying that the static pressure distribution measured is characteristic of the total pressure distribution. The increased uniformity in the pressure distribution should result in the following improvements: (1) increased turbine life, (2) decreased radial loads and shaft movements, which tend to produce increased clearances and/or rubbing, (3) reduction or avoidance of maldistributions of coolant flow, (4) reduction in deformation and cracking of sheet metal, and (5) decreased HPFT turbine temperatures for a given power level.

Both the static and total circumferential pressure variation downstream of the 180-degree turnaround duct (Fig. 19 and 20, respectively) were greatly reduced for the two-duct HGM configuration. 


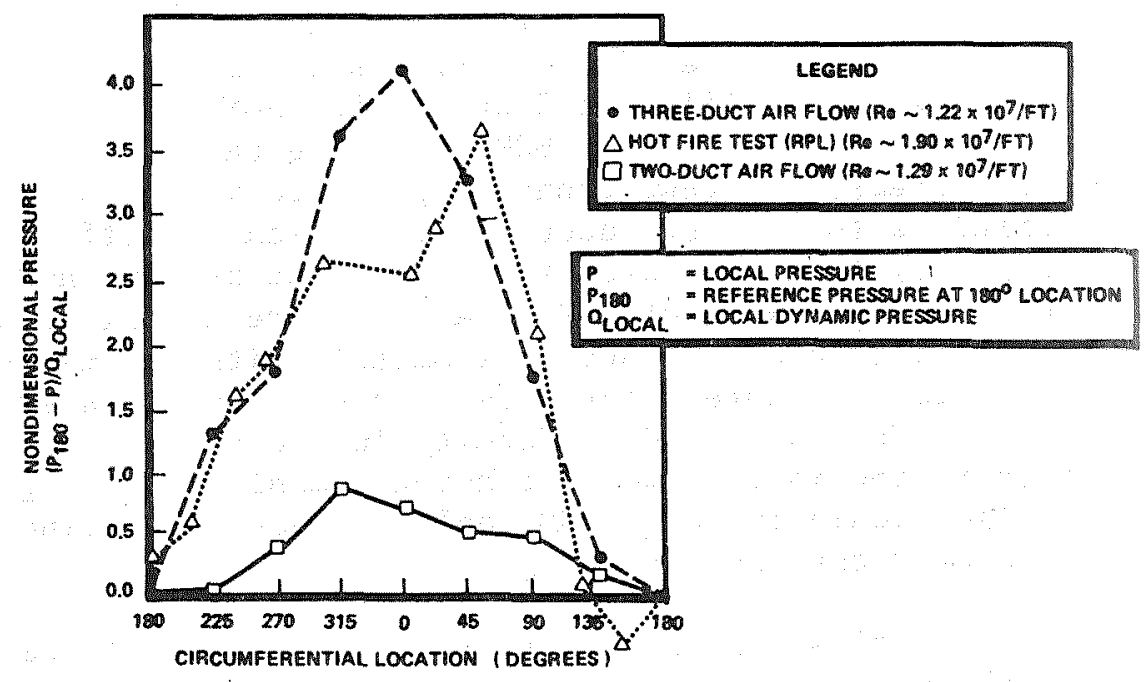

Fig. 19. Static Pressure Variation Downstream of 180-Degree Turn

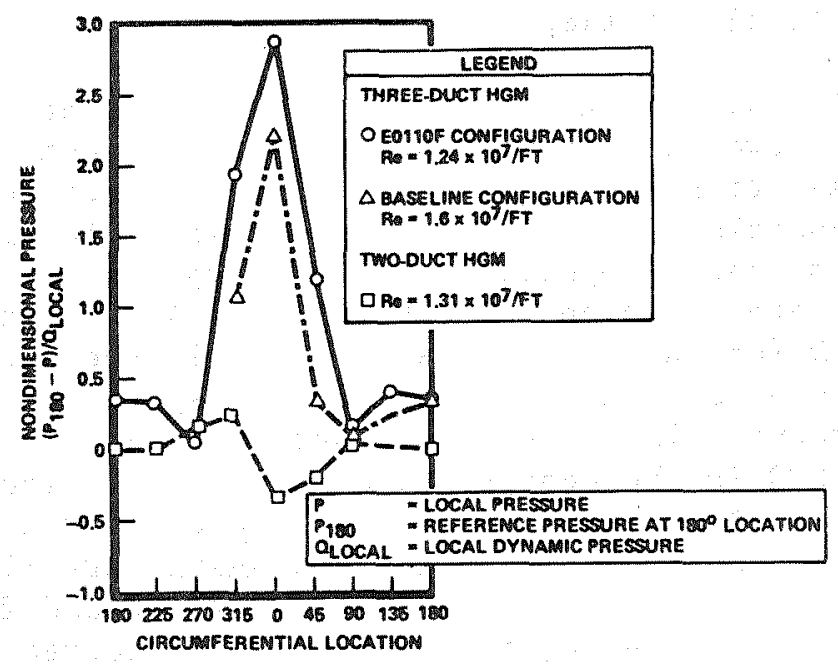

Fig. 20, Total Pressure Variation Downstream of Turnaround Duct 180-Degree Turn

Examination of Fig. 19 indicates the static pressure difference, referenced at the maximum pressure position at the 180-degree location, is approximately 25 percent of that exhibited in the present SSME HGM design. The minimum static pressure was recorded at 
the 315-degree location for the two-duct configuration while the three-duct configuration minimum static was identified at 0 degree for HGM air-flow tests and 45 degrees for SSME hot-fire tests. The total pressure circumferential pressure variation exhibited for the two-duct HGM is radically different (Fig. 20) from that associated with the present HGM design. The two-duct HGM total pressure distribution varies little and is nearly symmetric with the maximum total pressure located between the two transfer ducts. The increased uniformity in the turnaround duct region in the two-duct hot-gas manifold configuration would increase HGM coolant sheet metal liner life over the present design.

The flow through the transfer duct.exit planes of the two-duct manifold was more uniform than that present in the current three-duct manifold design. The improvement in flow uniformity should decrease main injector LoX posts loading and increase their operational lifetime.

The percentage of the flow area stagnant is less for the two-duct configuration. A rough comparison of stagnation areas for the two- and three-duct hotgas manifold configurations is displayed in Fig. 21 for comparable Reynolds numbers. Typical mass flow splits are 52 percent in the UTD and 48 percent in the LTD for the two-duct system, while the three-duct configuration exhibits typical mass splits of UTD: 52 percent, CTD: 9 percent, and LTD: 39 percent, where CTD is the center transfer duct. Typical Mach number profiles for the two- and three-duct hot-gas manifold configuration scaled to engine RPL (100 percent) conditions are shown in Fig. 22 and 23, respectively. The maximum Mach number observed in the two-duct configuration is 0.16 while the three-duct HGM exhibited a maximum Mach number of 0.26 .

Flow uniformity improvements for the two-duct HGM configuration are shown by examination of Fig. 24 and 25, where scaled air flow Mach number profiles along major transfer duct axes are plotted for 


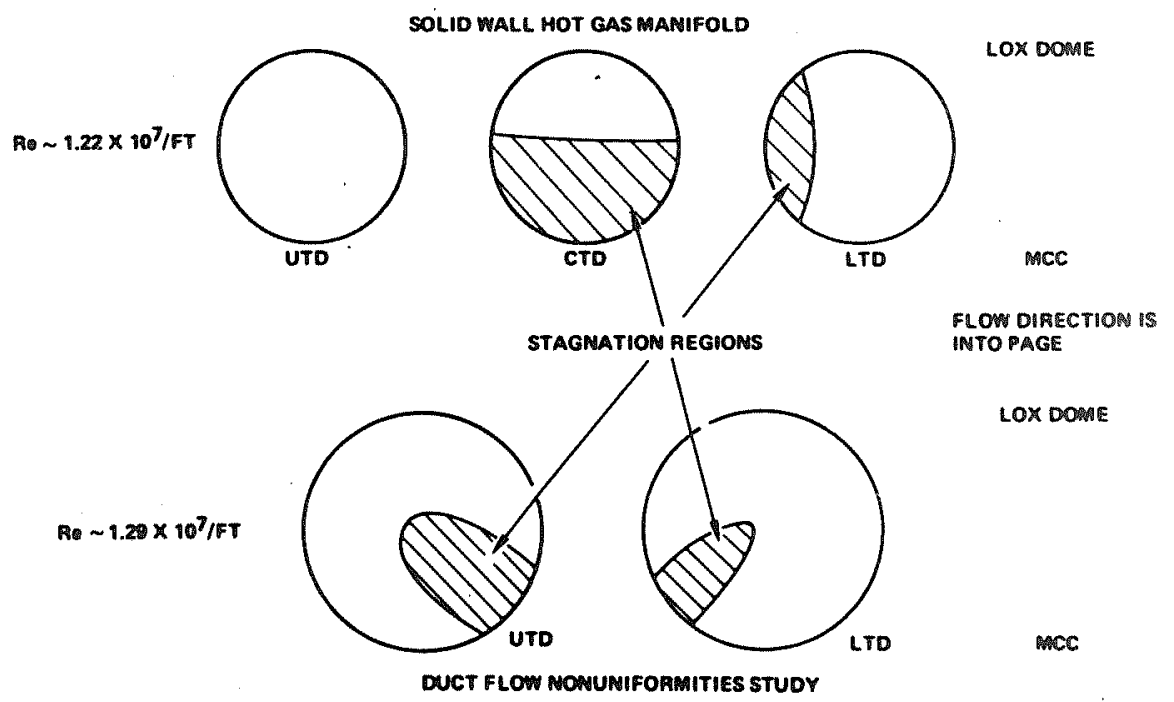

Fig. 21. Stagnation Region Comparison Between Two- and Three-Duct Configurations

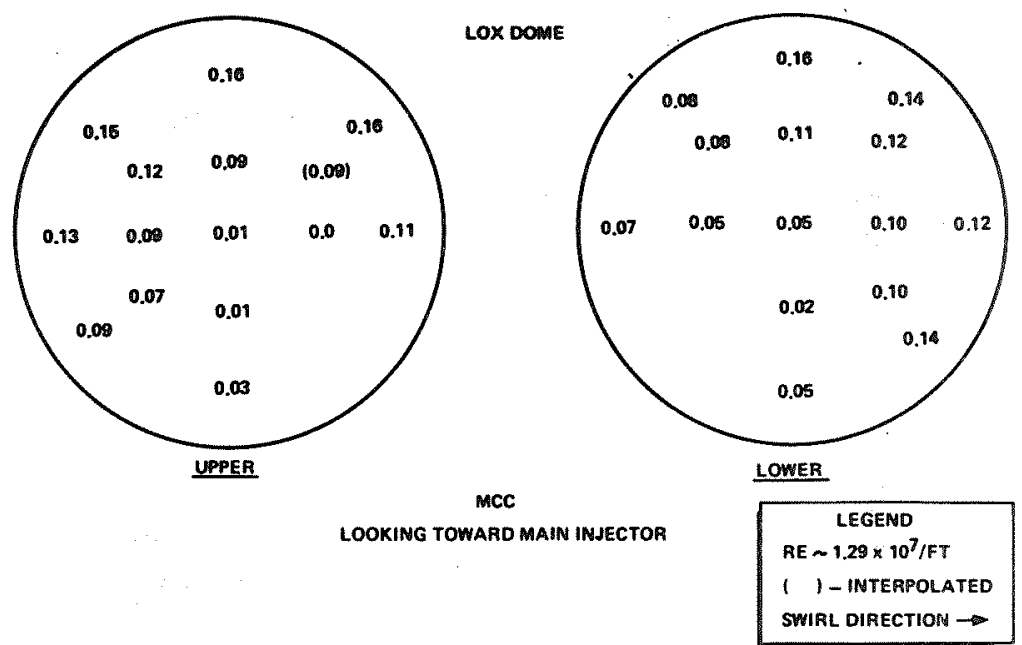

Fig. 22. Engine-Scaled Transfer-Duct Mach Number Profiles - Two-Duct HGM

both the three- and two-duct HGM configurations, respectively, for corresponding Reynolds number conditions. 



LOOKING TONARDS MAIN INJECTOR

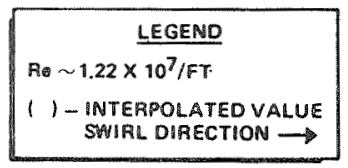

Fig. 23. Engine-Scaled Transfer-Duct Mach Number Profiles - Present Three-Duct SSME Design

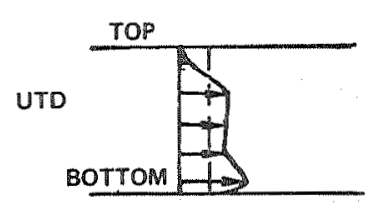

Re $\sim 1.22 \times 10^{7} / \mathrm{FT}$


Fig. 24. Engine-Scaled Three-Duct Manifold Mach Number Profiles Along Duct Major Axes (100 Percent Power Level Condition) 


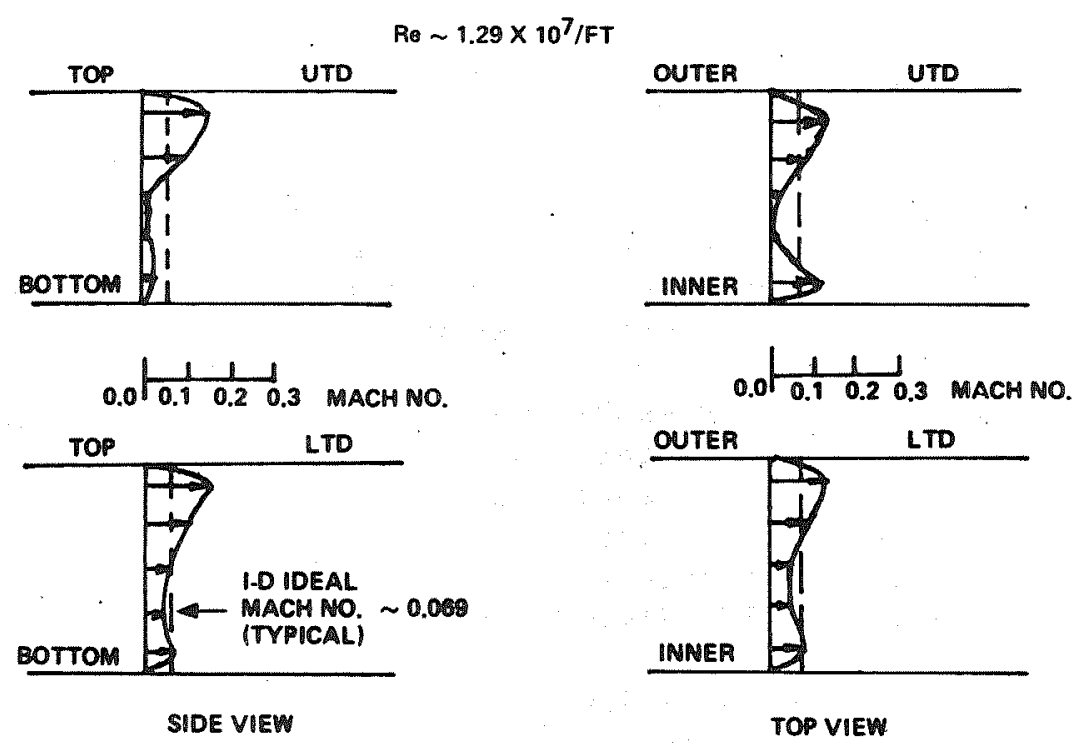

Fig. 25. Engine-Scaled Two-Duct Manifold Mach Number Profiles Along Duct Major Axes (100 Percent Power Level Condition)

It can be observed from the side view profiles (Fig. 25) that there is more flow in the upper portion of the ducts as expected because the flow has an upward bias after coming around the 180-degree turn. The contours of these vertical profiles are basically the same in both ducts. The top view shows that there is more flow on the outside of each duct. This is due to the fact that flow travels circumferentially in both directions around the fishbowl where most of the flow enters the transfer ducts at the outside regions. Examination of the corresponding Mach number profiles associated with three-duct manifold displays that little appreciable flow passes through the center transfer duct. In addition, the flow is nonuniform within each duct and from one duct to another. This observation is true for both the vertical and horizontal axis. Thw two-duct HGM configuration Mach number profiles for both ducts approach the onedimensional ideal Mach number condition (0.069). This ideal Mach number uniformity condition was only approached in the upper transfer duct in the present 
three-duct design. It should be noted that the onedimensional constant Mach number profile across the transfer duct exit plane is the best flow condition achievable for a given mass flow and transfer duct cross-sectional area. The flow through the transfer duct exit plane, in the two-duct HGM configuration, is clearly more symmetrical and uniform than that associated with the current three-duct HGM design.

Fluctuating pressures were measured, as previously mentioned, at four locations within the model. These miniature, high-frequency transducers were installed just upstream of the model inlet (hubcap), at the transfer duct entrance and exit and at the main injector racetrack CGIP (Fig, 7).

Results at cold-flow conditions for two flow conditions are displayed in Table 5. Values shown are composite RMS values in the frequency range of 0 to $2000 \mathrm{~Hz}$. Note that the fluctuating pressure at the transfer duct entrance is the highest measured for both tests. This may be due to flow separation from turbulence generated in the 180-degree turn in addition to separation effects resulting from flow entering the transfer ducts (Ref. 4). No predominant fluctuation frequency was found at any of the measurement locations. The trend indicated from these data. suggest that the highest fluctuating pressures are experienced at the entrance to the transfer ducts and decay downstream. This is based on only these four measurements.

Table 5. Fluctuating Pressure ( $\mathrm{P}^{\prime}$ ) Results

\begin{tabular}{|l|c|c|}
\hline \multirow{2}{*}{ Position } & \multicolumn{2}{|c|}{ Reynolds Number $\left(\operatorname{Re}_{\mathrm{p}}\right)$} \\
\cline { 2 - 3 } & $5.08 \times 10^{6}$ & $7.07 \times 10^{6}$ \\
\hline Hubcap Duct Entrance & $0.517^{*}$ & 0.514 \\
Transfer & 0.942 & 1.27 \\
Transfer Duct Exit & 0.867 & 1.12 \\
CGIP - Main Injector & 0.607 & 0.907 \\
Racetrack & & \\
\hline *(in psi) & \\
Note: PMS), Frequency Range $(0-2 \mathrm{kHz})$ \\
\hline
\end{tabular}




\section{Conclusions}

An advanced SSME hot-gas manifold design was successfully demonstrated that improved flow uniformity in the HGM turnaround duct and transfer duct exit regions over that exhibited in the present fuel-side three-duct HGM design. This advanced HGM design shows promise in leading to longer life, higher power level SSME designs, as well as having application to future liquid rocket engine systems.

In this study, tests were successfully conducted on the advaned two-duct HGM design over a Reynolds number range from 22 to 69 percent of 100 percent SSME power level conditions with transfer duct average Mach number held essentially constant (0.15 to 0.16$)$. For all tests conducted, little Reynolds number effect was observed on the data except in the fishbowl region where local dynamic pressure increase was observed in the low Reynodls number range. The HGM flow field exhibited 1ittle gross unsteadiness except in the transfer duct separation regions over the Reynolds number range investigated.

Major flow improvements, observed in the twoduct HGM design in the turbine exit/turnaround duct region, were accomplished by increasing the annular path cross-sectional area downstream of the 180degree turn, the fishbowl volume, and by contouring the two large transfer ducts with the outer fishbow1 housing. These features, in general, decreased the local dynamic pressure and allowed for adequate flow streamline relief required to gradually turn the flow into the transfer ducts in a more gentle manner than that exhibited by the present design. It was observed that the two-duct HGM turbine exit circumferentially pressure gradient was reduced by approximately 66 percent, while the total and static pressure distributions in the region downstream of the 180-degree turn were decreased by approximately 75 percent. These flow characteristics should improve turbine coolant distribution and increase liner Iife. 
Mow uniformity was improved in the transfer duct exit planes. However, separation phenomena accounted for approximately 25 percent of the total crosssectional area, and improved contouring of the inlets of these ducts could yleld still greater reduction in peak flow velocities. The maximum engine scale Mach number exhibited for the two-duct HGM configuration was reduced by 38 percent from that observed on the current design. The increased total cross-sectional area associated with the two enlarged transfer ducts is belleved to be the major contributing factor in duct exit flow improvement because of the corresponding decrease in average dynamic pressure. These twoduct HGM tralts should substantlally increase SSME main injector LOX post life.

\section{Acknowledgements}

This study was performed under NASA Contract NAS8-34507 under subcontract to Lockheed Missiles and Space Company, Inc. Huntsville, Alabama, Subcontract No. SM80C6620M. The exceptional support. given by the personel associated with this study is greatly appreciated. In particular, appreciation is expressed to Mr. Heinz Struck of NASA Marshall Space Flight Center; Mr. Alan Ratliff and Dr. Jurgen Thoenes of Lockheed Missiles and Space Company, Inc. Huntesville, AL; and Mr. F.M. Kirby, Mr.W. R. Wagner, and Mr. R. Kassner of Rocketdyne for their guidance. Support gïven by Mr. J. Rietdyk, Mr. T. Adams, and Mr. D. Peterson of Rocketdyne's Combustion Devices Group and Mr. J. Lindquist in the design and fabrication phases was instrumental in the success of this program. Commendation is also expressed to Mr. A. McKinstry, Mr. T. Hughes, and the NAAO Thermodynamic Laboratory test crew for their dedicated support associated with conducting the test program. Support gliven by Mr. J. Romero, Mr. J. Kingsley, and Ms. K. Gorham associated with the study data reduction task is appreciated. The exceptional support glven by Mrs. C. Greminger in formal documentation tasks associated with the program was also greatly appreciated. 


\section{$\underline{\text { References }}$}

1. Liang, P. Y., "An Inviscid Three-Dimensional Analysis of the Space Shuttle Main Engine Hot Gas Manifold," presented at the 18th Thermophysics Conference, Montrea1, Canada, 1-3 June 1983.

2. Thoenes, J., "Duct Flow Nonuniformities study," presented at Computational Fluld Mechanic Workshop, NASA MSFC, Huntsville, AL, 14 March 1984.

3. Rosen, R., Liang, P. Y., Quan, Y. H., Rao, G. V. R. and Yang, T. T., "Investigation of a Complex Rocket Engine Manifold Flow to Determine Its Major Characteristics," presented at AIAA/SAE/ASME 20th Joint Propulsion Conference, Cincinnati, Ohfo, Paper No. 84-1462, June 1984.

4. Pelaccio, D. G., Duct Flow Nonuniformities Study Final Report, Rocketdyne Report No. RI/RD83-160, Canoga Park, CA, 30 June 1983.

5. Lepore, F. F. and Vogt, S., Solld Wall Hot-Gas Manifold Testing Series IV Test Results, Rocketdyne Briefing No. AUT-83-006, Canoga Park, CA 13 January 1983.

6. Cheremisinoff, N. P., Fluid Flow Pumps, Pipes, and Channels, Ann Arbor Science Publications, Ann Arbor, Michigan, p. 125, 1981.

\section{Appendix A: Scaling Techniques}

Though geometric and dynamic similarity may exist between the cold-flow model and hot-fire engine operation, these conditions are not sufficient for the direct application of raw test data to an actual hotfire operation. Due to the difference in operating pressures, temperatures, and flowrates, a few conversion factors or scaling parameters must be utilized in order to convert raw cold-flow data to simulated hot-fire operations. Once the necessary scaling parameters have been calculated, the data base obtained from experiments can then be easily transformed into useful information directly applicable to hotfire engine operation. With reference to the type of 
experiments treated in this report, there are basic quantities for which scaling parameters may be obtained (Ref. 4): (1) steady-state pressure and (2) Mach number. In results discussed previously, scaling of steady-state pressure and Mach number. was performed and will be addressed here. The methods described have proven to be very effective in the prediction of flow field definttion in a hot-fire engine situation (Ref. 5).

When Reynolds number ( $R e$ ) similarity exists between model and engine operation, it can be inferred that Euler number ( $\mathrm{Eu}$ ) similarity also exists between air flow test conditions and hot-fire engine operation. The $\mathrm{Eu}$ is defined (Ref, 6) as:

$$
\mathrm{Eu}=\frac{\mathrm{P}}{\rho \mathrm{U}^{2}}
$$

where $P=$ pressure, $\rho=$ fluid density, and $U=$ onedimensional velocity.

In comparing an SSME powerhead (three-duct system) with the two-duct test model, it is more convenient to compare the Reynolds number per untt length rather than the nondimensional quantity, since there are major differences in the geometray, specifically: (1) SSME three-duct powerhead HGM with 4.9-inch exit diameter transfer ducts, while (2) the two-duct HGM has 6.5-inch constant diameter transfer ducts.

The Reynolds number per unit length is defined as:

$$
\frac{\mathrm{Re}_{\mathrm{D}}}{\mathrm{D}}=\frac{\mathrm{U}}{\mathrm{V}}=\operatorname{Re}
$$

where $D$ is the transfer duct diameter, $U$ the onedimensional gas velocity, and $\nu$ the kinetic viscosity. Table A-1 shows a Reynolds number comparison between varfous hot- and cold-flow conditions.

As Table A-1 suggests, the cold-flow Reynolds number per unit length achieved for full throttle is 
Table A-1. Two-Duct/SSME HGM Reynolds Number Comparison

\begin{tabular}{|c|c|c|c|c|c|c|}
\hline & \multicolumn{3}{|c|}{ COLD FLOW, 2-DUCT } & \multicolumn{3}{|c|}{ SSME*, HOT-FIRE } \\
\hline & $\begin{array}{l}\text { LOW } \\
\text { FLOW }\end{array}$ & $\begin{array}{l}\text { MEDIUM } \\
\text { FLOW }\end{array}$ & $\begin{array}{l}\text { MAXIMUM } \\
\text { FLOW }\end{array}$ & $\begin{array}{c}65 \% \\
\text { THROTTLE }\end{array}$ & $\begin{array}{c}\text { 100\% } \\
\text { THROTTLE }\end{array}$ & $\begin{array}{c}109 \% \\
\text { THROTTLE }\end{array}$ \\
\hline $\begin{array}{l}\text { FUEL MASS } \\
\text { FLOW (LBM/S) }\end{array}$ & 26.9 & 52.3 & 73.5 & 90.6 & 151.8 & 173 \\
\hline $\operatorname{Re} \times 10^{6}$ & 2.59 & 5.08 & 7.07 & 4.57 & 7.68 & 8.14 \\
\hline $\begin{array}{l}\operatorname{Re} / D \times 10^{7} \\
(1 / F T)\end{array}$ & 0.48 & 0.94 & 1.30 & 1.11 & 1.86 & 1.98 \\
\hline
\end{tabular}

well within the same order of magnitude as that exhibited by the SSME. In light of this trend, reference will be made exclusively to the full throttle (maximum flow) alr-flow conditions when cold-flow tests data are compared to hot-fire tests.

Differential pressure data are easily. scaled by use of the Euler number analogy between hot fire and cold flow, which has previously been discussed, as:

$$
\left.E u\right|_{\text {cold }}=\left.E u\right|_{\text {hot }}
$$

If a scaling factor is to be obtained for the difference in pressure between any two corresponding stations along a streamline designated as Station 1 and 2 , then $\mathrm{Eq} . \mathrm{A}-3$ can be rewritten as:

$$
\left.\frac{\mathrm{P}_{1}-\mathrm{P}_{2}}{\frac{1}{2} \rho \mathrm{U}^{2}}\right|_{\text {cold }}=\left.\frac{\mathrm{P}_{1}-\mathrm{P}_{2}}{\frac{1}{2} \rho \mathrm{U}^{2}}\right|_{\text {hot }}
$$

where both sides of the equation have been multiplied by $1 / 2$ for convenience. The above equation can be rewritten in more general terms as:

$$
\left.\frac{\Delta \mathrm{P}}{\mathrm{q}}\right|_{\operatorname{cold}}=\left.\frac{\Delta \mathrm{P}}{\mathrm{q}}\right|_{\text {hot }}
$$

where $\mathrm{q}$ is the dynamic head to convert a measured cold flow pressure differential $\left.\Delta \mathrm{P}\right|_{\text {cold }}$ to an equivalent 
hot-fire value, Eq. $(A-5)$ is solved for $\left.\Delta P\right|_{\text {hot }}$ :

$$
\left.\Delta \mathrm{P}\right|_{\text {hot }}=\left.\left(\frac{\left.\mathrm{q}\right|_{\text {hot }}}{\left.\mathrm{q}\right|_{\text {cold }}}\right) \Delta \mathrm{P}\right|_{\text {cold }}=\left.\mathrm{K} \Delta \mathrm{P}\right|_{\text {cold }}
$$

where $K$ is the scaling factor and varies only as a function of the mass flowrate, $\dot{\mathrm{m}}$.

Typical values of $\mathrm{K}$ for conversion to threeengine operating conditions of interest are given in Table A-2.

Table A-2. Typical Scaling Factors to Varlous Engine Power Levels. (Transfer Duct Exit Location)

\begin{tabular}{|r|c|c|c|c|c|c|}
\hline $\begin{array}{r}\text { TEST } \\
\text { NO. }\end{array}$ & $\begin{array}{c}\text { TIME } \\
\text { SLICE, } \\
\text { SECONDS }\end{array}$ & $\begin{array}{c}\dot{M}_{\text {FUEL }} \\
\text { LBM/SEC }\end{array}$ & $\begin{array}{c}1 / 2^{\mathrm{PU}}{ }^{2} \\
\text { PSID }\end{array}$ & \multicolumn{3}{|c|}{ SCALING FACTORS } \\
\cline { 5 - 8 } & $\begin{array}{c}\mathrm{K}_{\text {MPU, }} \\
65 \%\end{array}$ & $\begin{array}{c}\mathrm{K}_{\mathrm{RPU}}, \\
100 \%\end{array}$ & $\begin{array}{c}\mathrm{K}_{\mathrm{FPU}} \\
109 \%\end{array}$ \\
\hline 1.07 & 14.0 TO 14.7 & 61.63 & 2.169 & 5.52 & 10.08 & 11.80 \\
\hline
\end{tabular}

The dynamic pressure $\left.q\right|_{\text {hot }}$ is computed from engine balance values of fuel flowrate, $\dot{\mathrm{m}}$, gas temperature, $T$, and static pressure, $P_{s}$, and local cross-sectional area as defined in the relation below:

$$
\left.q\right|_{\text {hot }}=\left.\frac{\mathrm{RT}}{2 \mathrm{~g}_{\mathrm{c}} \mathrm{P}_{\mathrm{s}}}\left(\frac{\dot{\mathrm{m}}}{\mathrm{A}}\right)^{2}\right|_{\substack{\text { engine } \\ \text { balance }}}
$$

Similarly, $\left.q\right|_{\text {cold }}$ is obtained by use of $\mathrm{Eq} .(\mathrm{A}-7)$ where the physical quantitles are obtained from standard facility measurements.

Mach number values obtained from measured coldflow tests can be scaled to engine conditions by the ratio of the one-dimensional value of $M$ calculated for engine operation to those calculated for test model operations : 


$$
\mathrm{M}_{\text {hot }\left.\right|_{\text {local }}}=\left[\frac{\mathrm{M}_{\text {hot }}}{\mathrm{M}_{\text {cold }}}\right] 1-\left.\mathrm{D} \mathrm{M}_{\text {cold }}\right|_{\text {local }}
$$

The one-dimensional Mach number can be calculated either from the isentropic flow equations by use of the average total and static pressures measured in the test model, or from the low of conservation of mass by the formula glven below:

$$
\left.M\right|_{1-D}=\frac{\dot{m} R T}{P_{s} A} \sqrt{g_{c} \gamma R T}
$$

Equation (A-9) can be applied to both cold-flow and hot-fire operation since test data and engine balance theoretical values are both avallable for direct use. In determining the two-duct transfer duct onedimensional engine operational value, SSME HGM threeduct values must be adjusted to take Into account the difference in transfer duct total cross-sectional area is:

$$
A_{\text {two-duct }}=1.30 \mathrm{~A}_{\text {three-duct }}
$$

A typical value of the one-dimensional $M$ ratio, Eq. $(A-8)$, for engine operation at rated power level conditions is approximately 0.62 for the two-duct HGM configuration. This number varies as a function of engine and test model operation conditions. 